\title{
Strain evolution measurement at the microscale of a Dual Phase steel using Digital Image Correlation
}

\author{
H. Ghadbeigi, a, C. Pinna ${ }^{1, b}$, S. Celotto ${ }^{2, c}$ and J. R. Yates ${ }^{1, d}$ \\ ${ }^{1}$ The University of Sheffield, Department of Mechanical Engineering, \\ Mappin Street, Sheffield, S1 3JD, UK \\ ${ }^{2}$ Corus RD\&T, IJmuiden, The Netherlands \\ ah.ghadbeigi@sheffield.ac.uk, bc.pinna@shef.ac.uk, 'steven.celotto@corusgroup.com, \\ j.yates@sheffield.ac.uk
}

Keywords: DP steel, DIC, Strain, Microstructure

\begin{abstract}
Digital Image Correlation (DIC) together with in-situ tensile testing has been used to measure in DP1000 steel the evolution of plastic strains at the microstructure scale. Interrupted tensile tests were performed on specially designed samples and scanning-electron micrographs were taken at regular applied strain intervals. Patterns defined by the microstructural features of the material have been used for the correlation carried out using LAVision software. The full field strain maps produced by DIC show a progressive localisation of deformation into bands at about $45^{\circ}$ with respect to the loading direction. Plastic strains as high as $130 \%$ have been measured within the ferrite phase.
\end{abstract}

\section{Introduction}

Dual phase (DP) steels are widely used in the automotive industry since they combine high strength, high ductility as well as good formability [1]. DP steels consist of hard martensite islands dispersed throughout a soft ferrite phase. The micro-mechanical behaviour of this two-phase material is not well understood and this is a limiting factor for the development and application of future generation automotive steels.

Several attempts have been made to study the local deformation of advanced high strength steels including DP and TRIP steels [2]. Digital Image Correlation (DIC) has been used previously to measure strain distributions in DP steels [3, 4]. Tarigopula et al. [3] determined the evolution of strain localisation in DP800 steel at the macro scale during a shear test, but without any information about the contribution of each phase to the localisation process. Ososkov et al [4] used in-situ tensile tests to measure local strain partitioning in a DP600 steel before the onset of necking. They intermittently interrupted the test in a Scanning Electron Microscope (SEM) to take images and they analysed a relatively small area of the microstructure located away from the necking region. Following a small number of discrete points located either in a ferrite island or in a martensite rich region, that contained agglomerates of very fine ferrite and martensite particles, they also estimated the evolution of local deformation within each region. They reported plastic strain values inside the martensite rich regions and the ferrite phase as high as $30 \%$ and $70 \%$ respectively.

In the current study, in-situ micro tensile tests have been conducted in a SEM chamber to measure the evolution of plastic strain distributions in a DP1000 steel up to fracture. Micro-scale strain maps have been produced using DIC to study strain localisation in the material and its influence on damage.

\section{Experiments}

A commercial DP1000 steel grade with 50\% ferrite and 50\% martensite has been used in this study. The chemical composition of the material is given below in Table 1 . 


\begin{tabular}{|c|c|c|c|c|c|c|}
\hline wt $\% \mathrm{C}$ & wt $\% \mathrm{Mn}$ & $\mathrm{wt} \% \mathrm{Si}$ & $\mathrm{wt} \% \mathrm{Cr}$ & $\mathrm{wt} \% \mathrm{~V}$ & $\mathrm{wt} \% \mathrm{Ni}$ & $\mathrm{wt} \% \mathrm{Nb}$ \\
\hline 0.152 & 1.53 & 0.474 & 0.028 & 0.011 & 0.033 & 0.014 \\
\hline
\end{tabular}

Table 1: Chemical composition of the DP1000 steel studied

The specimen geometry shown in Fig.1a has been used to obtain the required strain levels given the capacity of the in-situ SEM load frame. All the specimens were manufactured from a $1.5 \mathrm{~mm}$ thick sheet with the loading direction parallel to the rolling direction. The samples were mechanically polished and etched first for 5 seconds in a 2\% Nital solution and then for 15 seconds in a $10 \%$ aqueous solution of sodium meta-bisulfite (SMB). The etched microstructure shows dark ferrite phase and white martensite of approximately equal volume fraction mix (Fig. 1b).

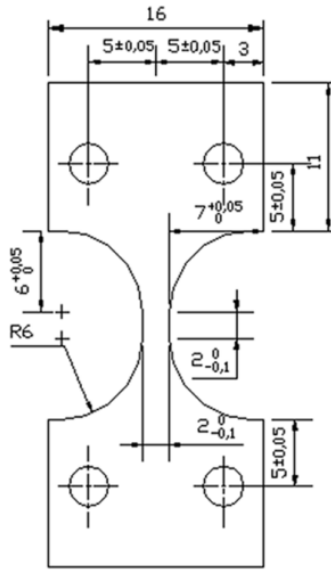

(a)

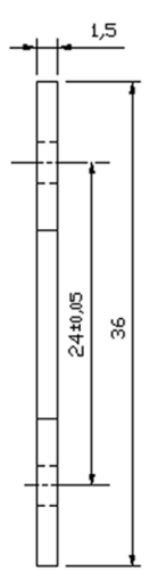

Fig 1: (a) micro-tensile test steel revealed by double etching using Nital and SMB solutions

A Deben MICROTEST tensile stage with a capacity of $5 \mathrm{kN}$ was used to carry out the tests. The machine was loaded in a CAMSCAN SEM, Fig. 2. The test was interrupted regularly, under loading to take images of a pre-selected area of the microstructure. This area was located as close as possible to the centre of the gauge length where necking was likely to take place. A very slow strain rate $\left(\dot{\mathrm{e}} \approx 0.001 \mathrm{~s}^{-1}\right.$ ) was selected to give sufficient time to follow the deformation of the microstructure. The test was stopped after the start of necking. The specimen was then removed from the stage and a layer about $400 \mu \mathrm{m}$ thick was removed from the specimen by mechanical polishing to eliminate the surface roughness created by the out of plane deformation. The microstructure was then revealed following the same procedure described. Fig. 3 shows the various steps of this procedure with the specimen loaded again in the microscope at the end. Micrographs were taken again regularly until the final fracture of the sample.

DIC was used to analyse the local plastic deformation at the scale of the microstructure using micrographs taken during the test. The micrographs were analysed using the commercial software, DaVIS 7.0 from LAVision [5] to determine the in-plane displacement field from which plastic strain values were calculated. Errors due to electron beam shift $[6,7]$ have been neglected in this study. The magnitude of the image shift has been estimated to less than 0.5 pixels for the imaging setup used in this research. This leads to a strain error of the order of $0.1 \%$ which is very small compared to the high strain values reported in the next section.

Sequential cross correlation has been carried out between successive images and the final displacement map corresponds to the summation of the incremental displacement vectors computed for each interrogation window. The strain values were then calculated by differentiating the final displacement maps. The microstructural features of the material have been directly used to correlate the images between two successive loading steps. A multi-pass algorithm [5] leading to a $2.2 \mu \mathrm{m}$ by $2.2 \mu \mathrm{m}$ final interrogation window with $75 \%$ overlap between windows was used to make the 
correlation work. A displacement accuracy of 0.01 pixels was obtained with a strain resolution of about $0.1 \%$. Strain maps were then produced over an area of $57 \mu \mathrm{m}$ by $45 \mu \mathrm{m}$ and the appearance of damage was then studied in relation to local strain distributions.

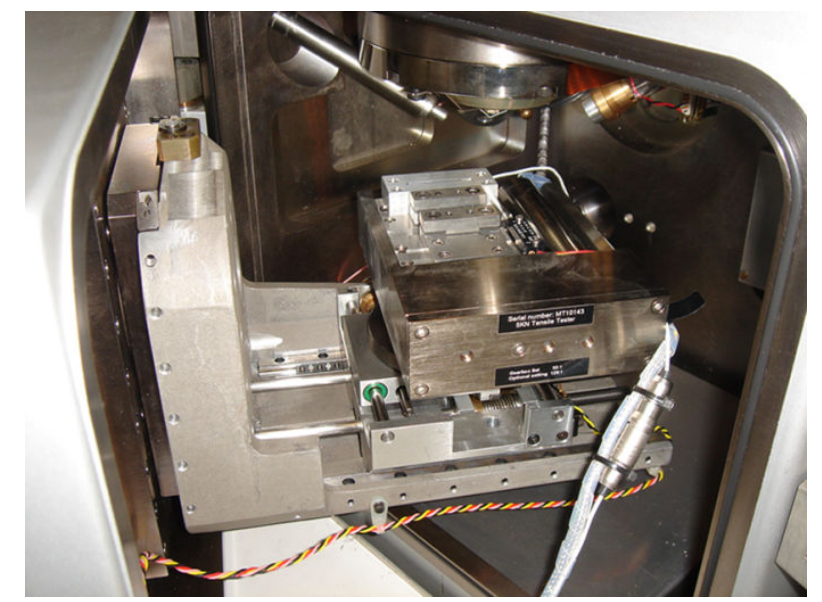

Fig. 2: Tensile test stage loaded in the SEM chamber

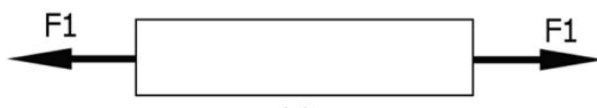

(a)

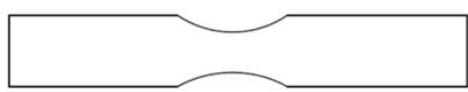

(b)

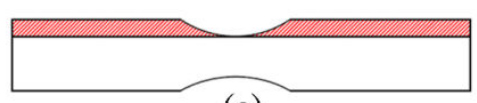

(c)

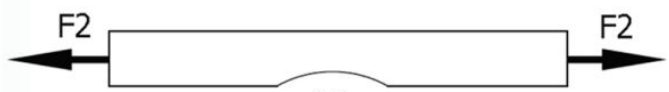

(d)

Fig. 3: (a) The specimen is loaded for the first step of the test, (b) necking occurs at the centre of the gauge section, (c) the deformed layer at the surface is removed by mechanical polishing and (d) the specimen is loaded again after etching until final fracture

\section{Results}

The engineering stress-strain curve shown in Fig. 4 is obtained from the test by measuring the elongation of the $2 \mathrm{~mm}$ long gauge section. The elongation of the gauge section was calculated by subtracting the elastic contribution of the machine to the total displacement measured by the LVDT. The large post uniform elongation in Fig. 4 is due to the effect of the gauge section geometry, which provides an opportunity to study damage development in the material. The small stress variations along this curve correspond to the test interruptions needed to take the micrographs for subsequent DIC analysis.

Fig. 5 shows the micrographs of the selected regions at the beginning of each loading step. Distributions of the microscale engineering strain component $\mathrm{E}_{\mathrm{yy}}$, along the loading direction (which is vertical on the pictures), together with the micrographs of the deformed material at the end of each step are shown in Fig. 6. Figures $6 \mathrm{a}$ and $6 \mathrm{~b}$ correspond to a macro strain of about $22 \%$ at the end of the first step and reveal the heterogeneity of the local deformation with strain values as high as $65 \%$ in the highlighted area. 


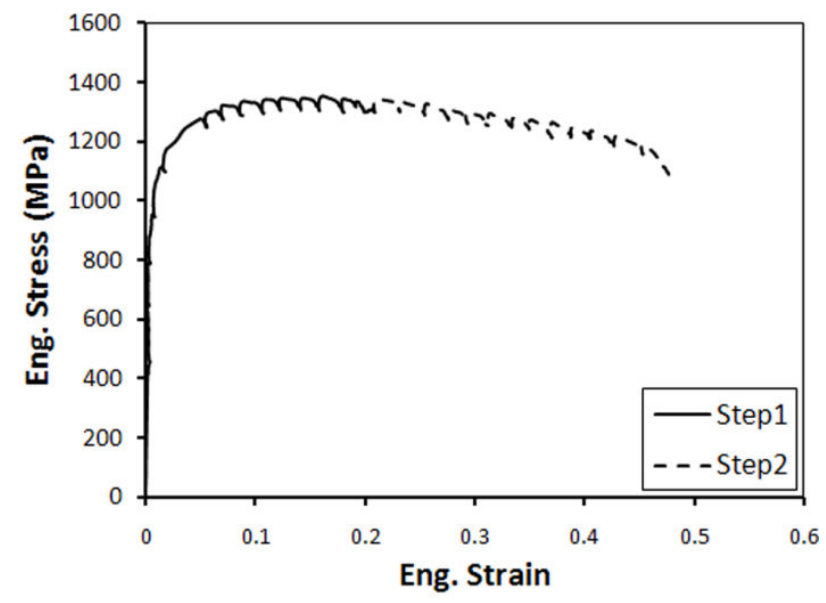

Fig. 4: Engineering stress-strain curve obtained from elongation of the gauge section

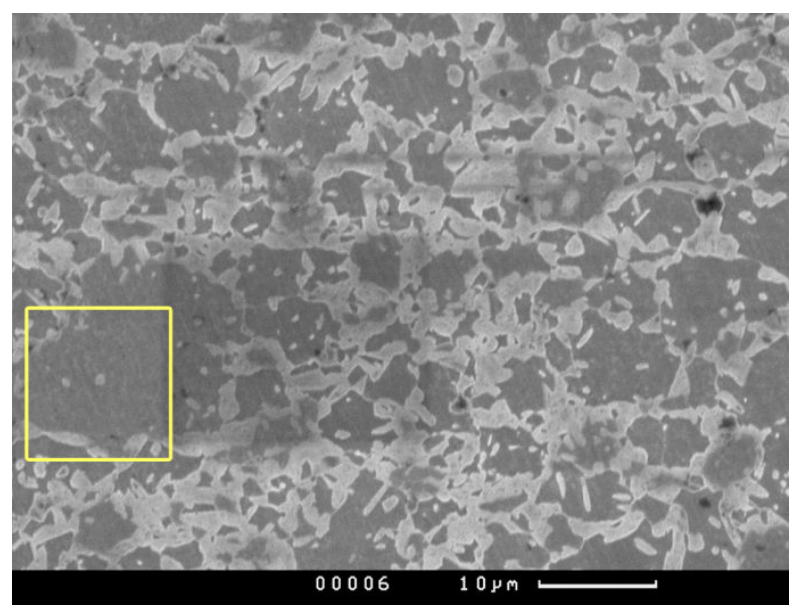

(a)

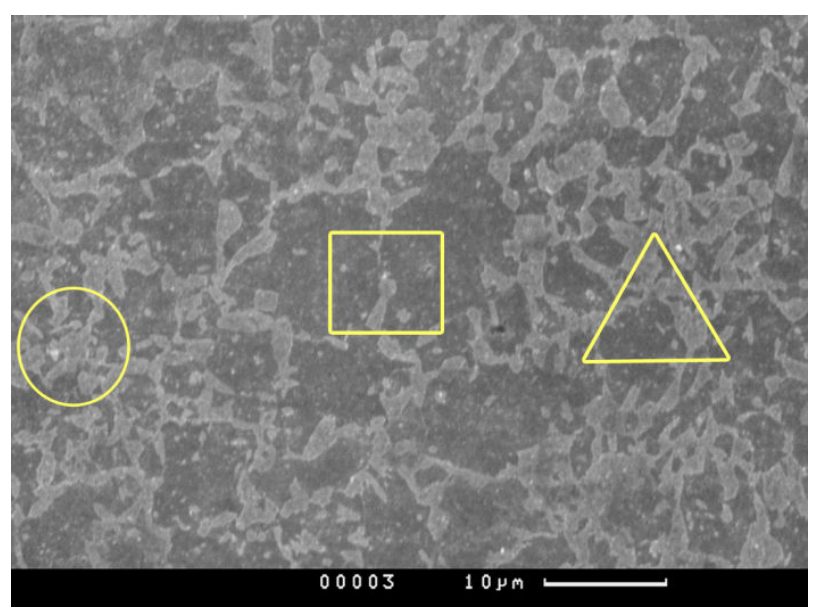

(b)

Fig. 5: Undeformed microstructure of the selected regions at the beginning of (a) the first and (b) the second loading step.

Localised bands of deformation have formed at $45^{\circ}$ with respect to the loading direction, with the highest strain values located within a large ferrite island where slip bands can be observed. Results also show that the martensite phase experiences large strain values as high as 35\% locally. Figures $6 \mathrm{c}$ and $6 \mathrm{~d}$ show the deformed microstructure and corresponding strain map at a macro strain of $45 \%$ prior to the final fracture. Since the microstructure at the beginning of the second step does not correspond to the microstructure at the end of the first step, due to the material removal after polishing, the two strain maps for steps 1 and 2 cannot be added directly. The highlighted regions in Fig. $6 \mathrm{c}$ show some damage sites that have appeared on the surface. Plastic strain values as high as $70 \%$ have been measured locally inside the highlighted regions (Fig. 6d). The produced strain map shows again localised deformation bands that follow the path created by slip bands in ferrite islands with the appearance of damage sites at the location of high strain values in either the ferrite (square area) or the martensite phase (circle).

The measured strain values in Fig. 6 show that the material can experience very large plastic deformation (with local strain values higher than 100\%), if the contributions of the two steps are added together, while the macro strain value is only $45 \%$. Extensive plastic deformation takes place within both the ferrite and martensite for this DP1000 steel, without any observation of failure along the interface between the two phases. Further investigation is however required to understand better the damage initiation and propagation mechanisms that operate in this material using the procedure developed in this study. 


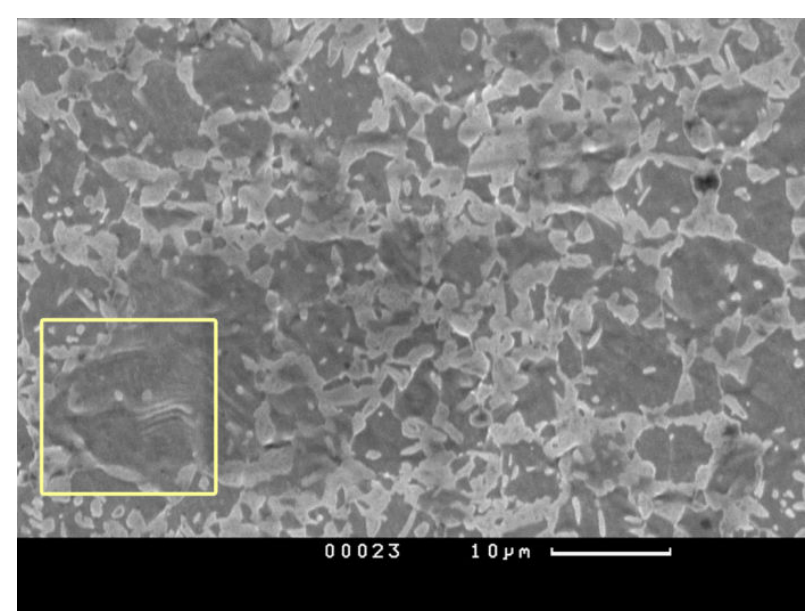

(a)

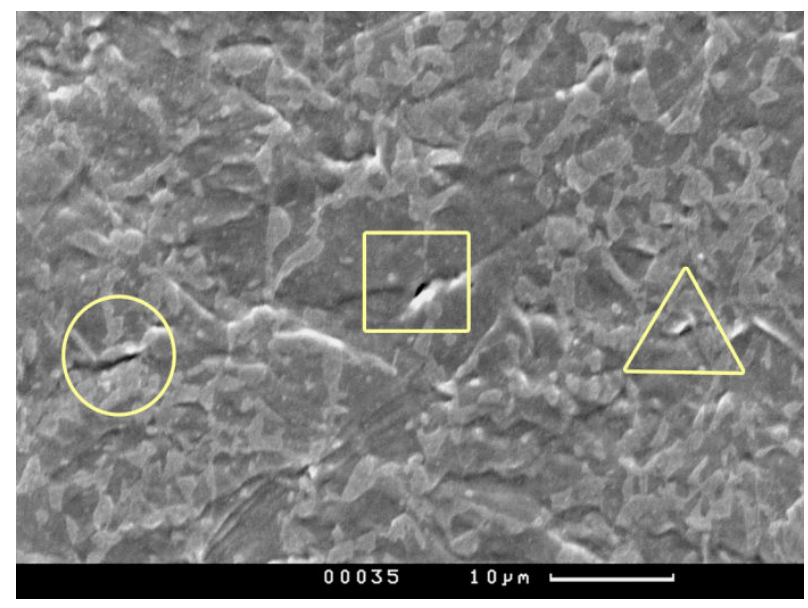

(c)

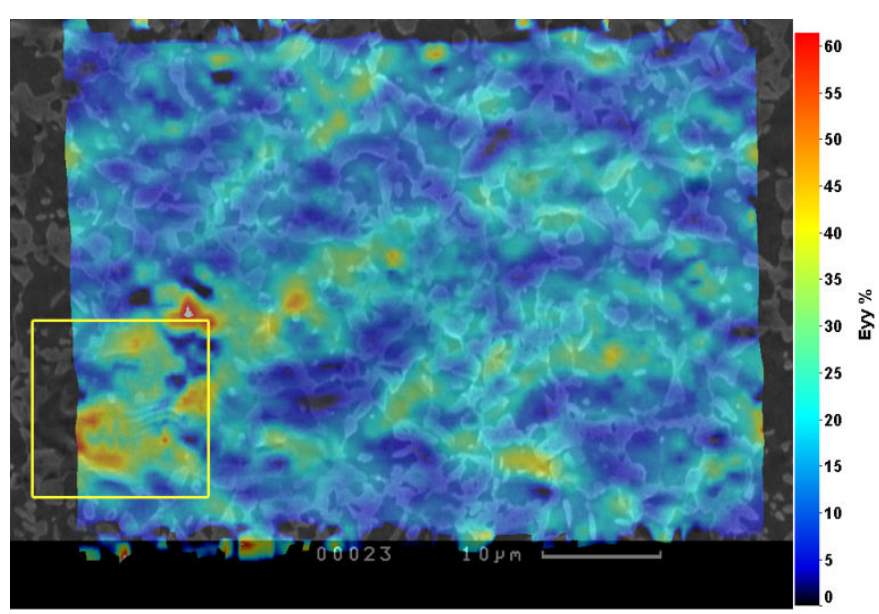

(b)

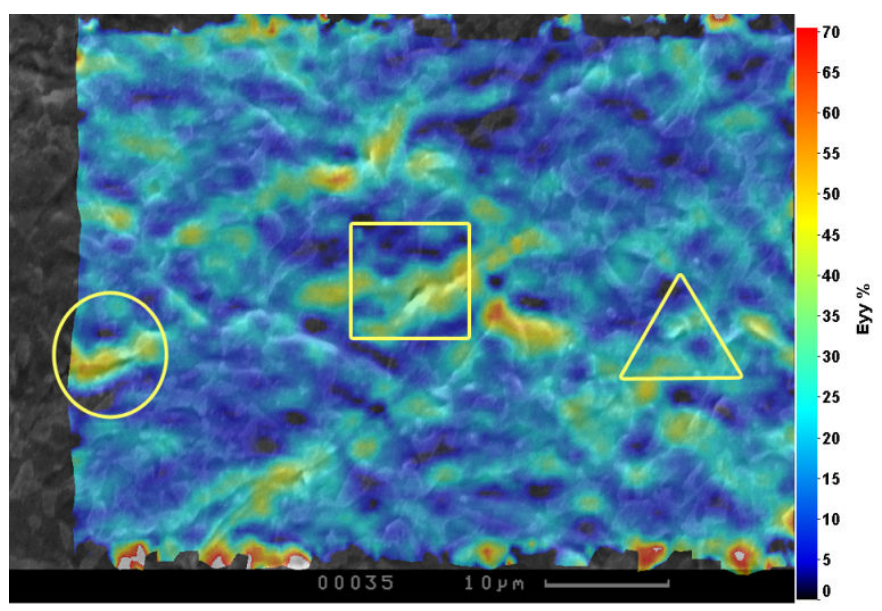

(d)

Fig. 6: (a and c) Micrographs of the deformed microstructure after steps 1 and 2, and (b and d) the corresponding strain maps superimposed onto the deformed microstructures (the loading direction is vertical on these pictures)

\section{Conclusions}

In-situ micro tensile tests have been carried out up to fracture on DP1000 steel to measure local plastic strain values at the scale of the microstructure using DIC. A progressive formation of localised bands orientated at $45^{\circ}$ with respect to the tensile direction has been observed and provides physical insight into the localisation of deformation in this two-phase steel. Both ferrite and martensite experience large plastic deformation before the onset of local damage with strain values as high as $120 \%$ and $35 \%$ measured in the ferrite and in the martensite phases respectively. The effect of the deformability of martensite on damage initiation and evolution in various DP steels can therefore be studied using the experimental procedure developed in this work.

\section{Acknowledgements}

The authors would like to thank EPSRC (Grant number EP/F023464/1) for financial support and CORUS RD\&T, IJmuiden in the Netherlands for providing the material of this study. 


\section{References}

[1] T. Senuma: ISIJ INT. Vol. 41 (2001), p.520

[2] S. Oliver, T.B. Jones and G. Fourlaris: Mater. Charact. Vol. 58 (2007), p. 390

[3] V. Tarigopula, O.S. Hopperstad, M. Langseth, A.H. Clausen, F. Hild, O.-G. Lademo and M. Eriksson: Exp. Mech. Vol. 48 (2008), p. 181

[4] Y. Ososkov, D.S. Wilkinson, M. Jain and T. Simpson: Int. J. Mater. Res. Vol. 98 (2007), p. 664

[5] LAVision, Davis Strain master Software. 2005.

[6] M.A. Sutton, N. Li, D.C. Joy, A.P. Reynolds and X. Li: Exp. Mech. Vol. 47 (2007), p. 775

[7] M.A. Sutton, N. Li, D. Garcia, N. Cornille, J.J. Orteu, S.R. McNeill, H.W. Schreier, X. Li and A.P. Reynolds: Exp. Mech. Vol. 47 (2007), p. 789 